University of Wollongong

Research Online

Faculty of Engineering - Papers (Archive)

Faculty of Engineering and Information

Sciences

March 2001

\title{
Results of AC loss tests on twisted and untwisted HTSC tape exposed to an external field
}

T. Hardono

University of Wollongong

C. Cook

University of Wollongong, chris_cook@uow.edu.au

F. Darmann

University of Wollongong

Follow this and additional works at: https://ro.uow.edu.au/engpapers

Part of the Engineering Commons

https://ro.uow.edu.au/engpapers/19

\section{Recommended Citation}

Hardono, T.; Cook, C.; and Darmann, F.: Results of AC loss tests on twisted and untwisted HTSC tape exposed to an external field 2001.

https://ro.uow.edu.au/engpapers/19

Research Online is the open access institutional repository for the University of Wollongong. For further information contact the UOW Library: research-pubs@uow.edu.au 


\title{
Results of AC Loss Tests on Twisted and Untwisted HTSC Tape Exposed to an External Field
}

\author{
Tri Hardono, Christopher D. Cook, and Frank Darmann
}

\begin{abstract}
This paper presents the results of magnetic loss tests on twisted and untwisted 37 multifilaments tapes exposed to an alternating field at power frequencies. The losses are measured using calorimetric methods, which are capable of measuring losses in short tapes with the accuracy of several microwatts per centimeter of tape. The losses of the tape due to the longitudinal field of the untwisted tape agree well with theoretical calculations. The measurement results on the twisted filament tape, with 50-mm twist pitch, show that the losses are slightly lower than that in the untwisted tape. This is due to the reduction of the coupling losses between the filaments in the tape. It is also shown that in the presence of normal fields, the losses are about one order higher than for longitudinal fields because of the anisotropic properties of the superconducting parts and because of the existence of eddy current loss in the silver sheath.
\end{abstract}

Index Terms-Magnetic losses, calorimetry, high temperature superconductors, power engineering.

\section{INTRODUCTION}

$\mathrm{B}$ $\mathrm{i}-2223 / \mathrm{Ag}$ wires technology promises significant benefits for power engineering applications in the near future. Much of the effort for the improvement of superconductors has been provided by the introduction of multifilamentary wire, which improve their electrical and mechanical properties. The effect of magnetic fields on the properties of HTSC has been widely investigated both in relation to the field strength and the orientation of the field to the sample $[1,3-4]$.

Manuscript received September 17, 2000. Revised November 24, 2000. This work was financially supported in part by the Australian Agency for International Development and the Energy Rescarch and Development Corporation.

T. Hardono is with the University of Wollongong, Wollongong NSW 2522 Australia (telephone: 61-2-42213535, e-mail: th10@uow.edu.au).

C. D. Cook is with the University of Wollongong, Wollongong NSW 2522 Australia (telephone: 61-2-42213086, e-mail: chris_cook@uow.edu.au).

F. Darmann is with the Australian Superconductors, PO Box 21 Gloucester Boulevard, Port Kembla, NSW 2505, Australia (telephone: 61 2-42266330, e-mail: htscdev@ozemail.com.au).
The Bi-2223/Ag wires can now be fabricated by a powderin-tube technique up to lengths of 1.25 kilometre. This technique leads to a better grain alignment of the HTSC material in the wires and critical transport current densities $J_{\mathcal{C}}$ of $23.3 \mathrm{kA} / \mathrm{cm}^{2}$ have been achieved [5]. This allows new applications such as current limiters, electrical cables and transformers to be built. It is important for prospective applications that the AC loss behaviour of HTSC in alternating magnetic fields or currents and their loss mechanisms are well understood. This allows the development of measures for reducing these losses by suitable conductor design. For example, twisting the filaments of the wire will result in the reduction of $\mathrm{AC}$ losses of the wire [6]. Also introducing an alloy wire sheath will enhance the performance of the wire [5,7].

This paper will describe methods of measuring losses of short HTSC samples subjected to an alternating field using calorimetric methods. In this work the losses of 37 multifilamentary twisted and untwisted samples exposed to a $50 \mathrm{~Hz}$ field are measured and analyzed. The behavior of the losses of the samples corresponds to theoretical approximations.

\section{TEST-RIG DESIGN AND CALIBRATION}

This section describes the instrumentation test rig design for AC loss measurements of HTSC samples using calorimetric methods. Calibration works that are needed before the experimental work will also be described. There are two kinds of calibration curves in this work, a calibration curve for the solenoid-generating magnetic field, and a calibration curve for the calorimeter system.

\section{A. Test-Rig Design}

For the measurement of AC losses of HTSC wires, the test rig instrumentation consists mainly of the calorimeter and other instrumentation such as current sources, digital multimeters and solenoid generated alternating fields. Most of the instrumentation is connected to a PC containing a data collecting system. The block diagram is depicted in Fig. 1. Detailed test instrumentation can be found elsewhere [4].

\section{B. Calibration of the Solenoid Generating Magnetic Field}

The purpose of this calibrating work is to determine the solenoid constant that is used to calculate the magnitude of the magnetic field as functions of the $\mathrm{AC}$ current flowing in 
it. The calibration curve is presented in Fig. 2. It can be seen that the constant is 5.7423 , which indicates that $1 \mathrm{~A}$ of $\mathrm{AC}$ current generates about $5.7 \mathrm{mT}$.

\section{Performance of the Calorimeter}

During the immersion of the calorimeter in liquid nitrogen, the temperature of the calorimeter exponentially reduces to $77.4 \mathrm{~K}$. Fig. 3 shows the performance of the calorimeter from room temperature to liquid nitrogen temperature. It can be seen that the temperature is constant after 800 seconds or about 14 minutes.

After the temperature becomes stable some measurements can be done. Fig. 4 depicts the performance of the calorimeter for a temperature increase of $125 \mathrm{mK}$ due to the power dissipation of the heater. The heater was turned on and off four times. We see that the temperature follows the dissipated energy from the heater. After four cycles the final temperature is back to the original temperature, which indicates that the calorimeter has high repeatability.

Fig. 5 shows that the calorimeter has a very quick response to the heat dissipated by the heater or sample. The time constant of the calorimeter is about 4.3 seconds, which means that measurements can be made quickly.

The purpose of the calorimeter calibration is to determine the thermal resistance of the calorimeter system. This work is done prior to each run of $\mathrm{AC}$ loss measurements of a sample.

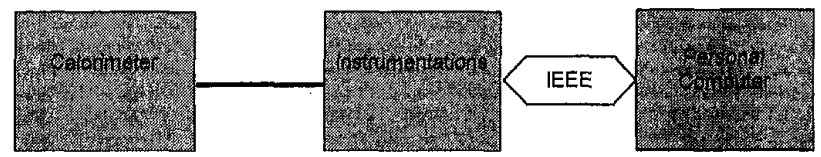

Fig. 1. Block diagram for $\mathrm{AC}$ loss measurements.

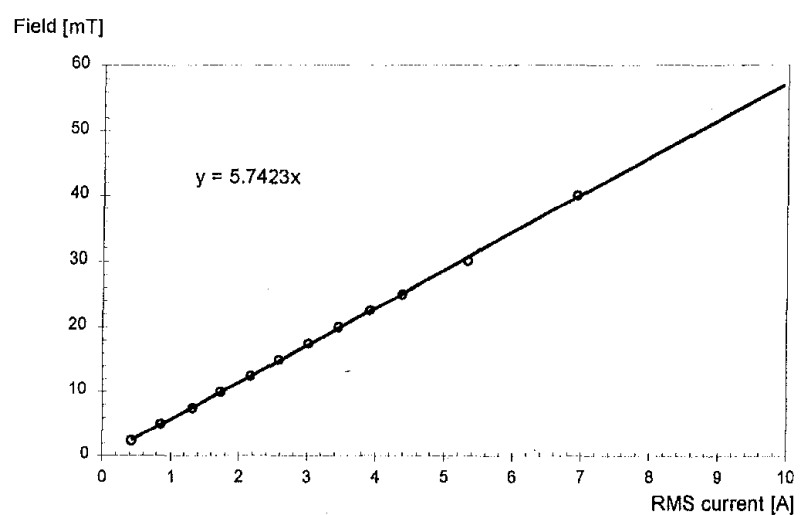

Fig. 2. Calibration curve of the solenoid generating ac magnetic field.

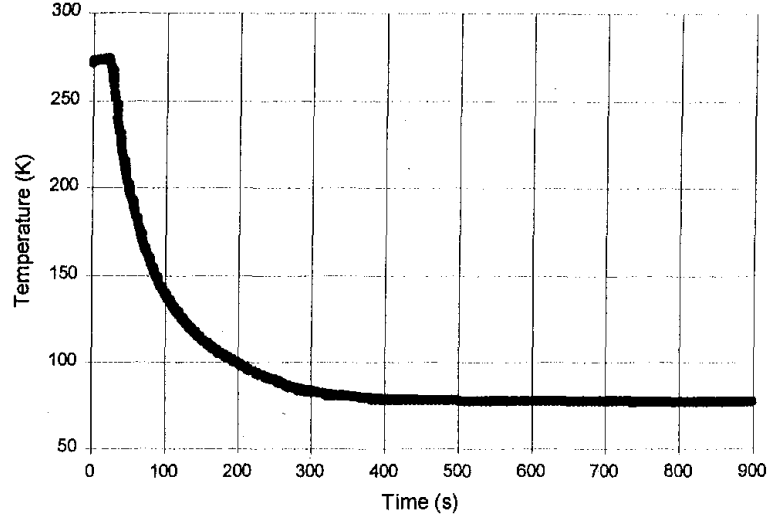

Fig. 3. Performance for the calorimeter during the immersion in liquid nitrogen.

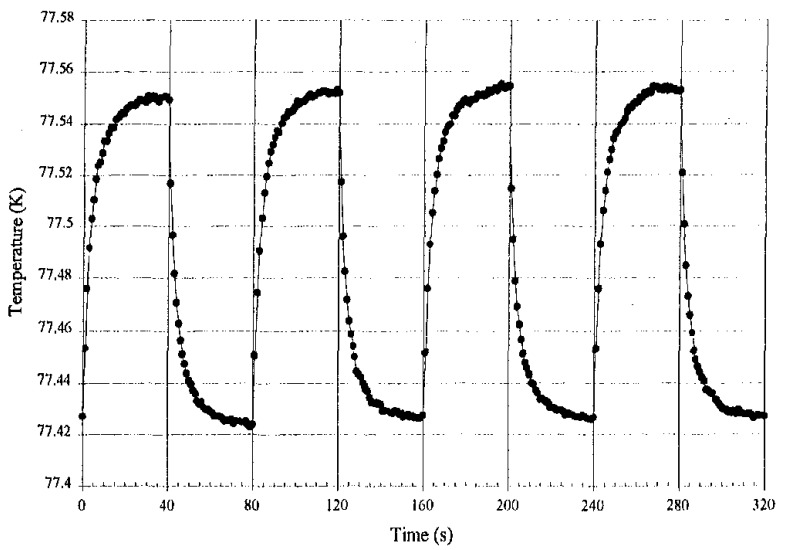

Fig. 4. Calorimeter performance during 4 cycles on off of the heater.

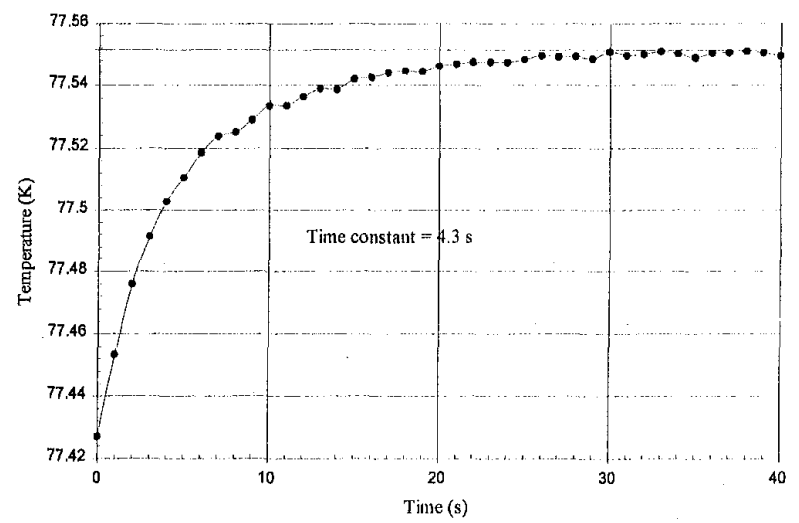

Fig. 5. Calorimeter performances for a temperature increase.

The power loss of the heater is equal to

$$
Q=I^{2} R_{h}
$$

where $Q$ is the loss, $I$ is the current and $R_{h}$ is the heater resistance. A typical calibration curve is given in Fig. 6 .

Passing an AC current through a solenoid coil generates an alternating field. The $\mathrm{AC}$ loss measurement was conducted by switching on the $\mathrm{AC}$ current source to the solenoid for 
period $\tau_{m}$ and recording the temperature rise $\Delta T$. This is repeated for different magnitudes of applied field. In this work the field is assumed to be homogeneously distributed within the sample length as confirmed in Fig. 7 and Fig. 8 generated using finite element method.

Table 1 provides an overview of the sample configurations for these measurements.

TABLE 1

SAMPLE CONFIGURATIONS

\begin{tabular}{cccccc}
\hline Sample & $\begin{array}{c}\text { Number } \\
\text { of } \\
\text { filaments }\end{array}$ & $\begin{array}{c}\text { Thickness } \\
(\mathrm{mm})\end{array}$ & $\begin{array}{c}\text { Width } \\
(\mathrm{mm})\end{array}$ & $\begin{array}{c}\text { Twist pitch } \\
\text { length }(\mathrm{mm})\end{array}$ & $\begin{array}{c}I_{c} \\
(\mathrm{~A})\end{array}$ \\
\hline MF-37 & 37 & 0.26 & 3.62 & $\infty$ & 24 \\
MF-37T & 37 & 0.26 & 3.62 & 50 & 25 \\
\hline
\end{tabular}

The total loss, $P_{t}$, of the superconducting sample is calculated using:

$$
P_{t}=\frac{\Delta T}{R_{t h}}
$$

where $\Delta T$ is the temperature increase and $R_{t h}$ is the thermal resistance of the calorimeter.

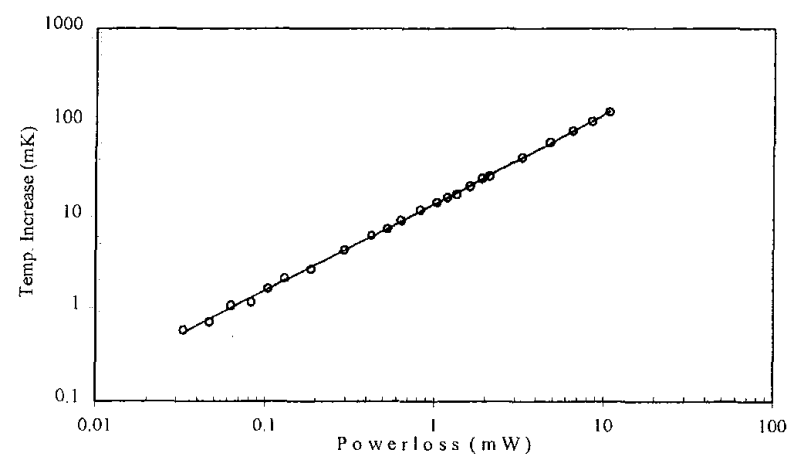

Fig. 6. Calibration curve of the calorimeter. The thermal resistance of the calorimeter was determined using this curve.

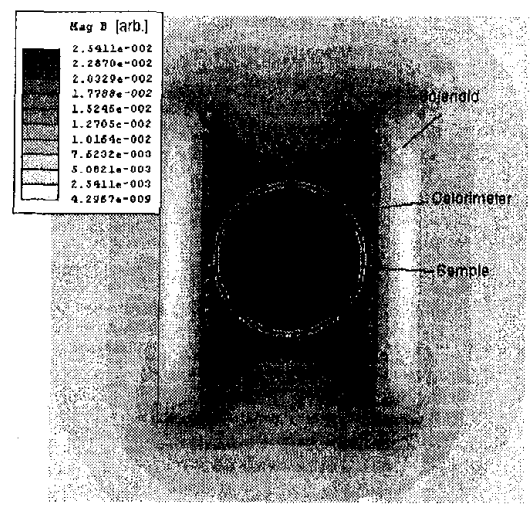

Fig. 7. Field map generated in the solenoid.

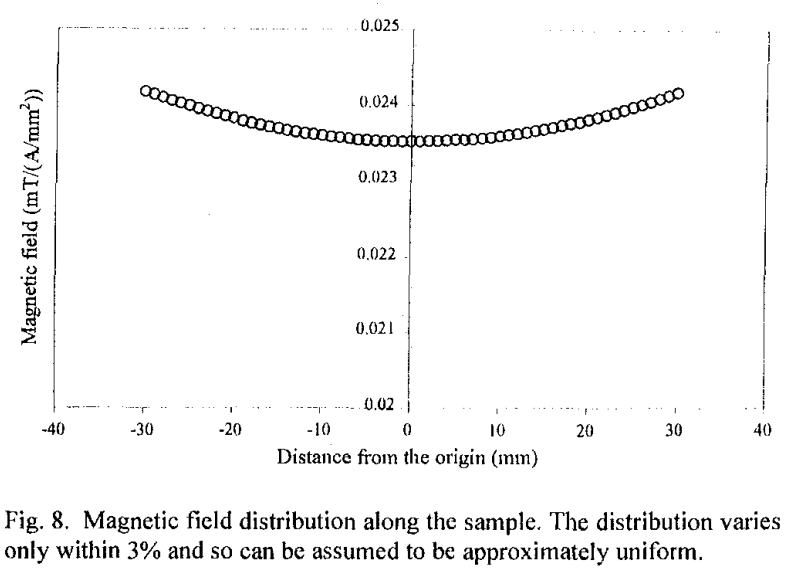

\section{RESULT AND DISCUSSION}

The theoretical calculation and initial results obtained from the calorimetric measurement of the losses of the sample subjected to a longitudinal and normal alternating field will be presented in this section.

\section{A. Theoretical Approximation}

If the sample were pure silver, the eddy current loss can be calculated using [2]

$$
P_{e}=\frac{8 \pi^{2} f^{2} B_{m}^{2} a^{3} d}{3 \rho}
$$

where $f$ is the AC frequency $(50 \mathrm{~Hz}), B_{m}$ is the peak value of applied field, $a$ and $d$ are the half width and thickness of the wires respectively and $\rho$ is the resistivity of the silver at $77 \mathrm{~K}$. In fact the eddy current losses are also generated in the heater, which is made of silver strip with the same dimension as the sample. Therefore the total eddy current loss is double that given by (3).

The hysteresis losses of the sample are approximated using the following equations:

$$
P_{h}=\alpha \frac{8 a d B_{m}^{3} f}{3 \mu_{0} B_{p}}
$$

for $B_{m}<B_{p}$, and

$$
P_{h}=\alpha \frac{8 a d B_{m} B_{p} f}{\mu_{0}}\left(1-\frac{2 B_{p}}{3 B_{m}}\right)
$$

for $B_{m} \geq B_{p}$

where $B_{p}$ is the full penetration of longitudinal field and is equal to $\mu_{0} J_{c} a, J_{c}$ is the critical current density of the sample, and $\alpha$ is a factor of $2 / 3$ as discussed by Ishii et al. by assuming that the cross-section of the superconducting cores is an ellipse and that the magnetic flux applies longitudinally to the longer axis of the core. 


\section{B. Measurement Results}

Fig. 9 shows the results of the AC loss measurement for the 37-multifilamentary samples exposed to a longitudinal and normal alternating field. The filled circles and squares indicate the loss results of twisted sample while the empty circles and squares are for untwisted sample. The thin dashed line indicates the eddy current component of the silver parts calculated using (3) and the thick solid line represents the approximation of the hysteresis loss using (4) and (5).

At $50 \mathrm{~Hz}$ frequency it is evident that the hysteresis loss is significant because its value is nearly two orders higher than the eddy current component. For the region below $30 \mathrm{mT}$ the value of the hysteresis loss is lower than the estimation and it is higher beyond that point. The existing coupling loss between the filaments that is significant at relatively high magnetic field can cause this. The losses of the tape due to the longitudinal field of the untwisted tape agree well with theoretical calculations. The measurement results on the twisted filament tape, with 50-mm twist pitch, show that the losses are slightly lower than that in the untwisted tape. This is due to the reduction of the coupling losses between the filaments in the tape.

When the sample is subjected to a normal field the loss becomes more than one order higher for the same magnitude of the field as can be seen in that figure. This is due to the anisotropic behavior of the grains in the sample. The field applied normal to the grain causes local current and hence the total losses become high.

\section{CONCLUSIONS}

A calorimeter has been used to measure the total losses of HTSC samples with the accuracy of microwatts per centimeter. In this work the $\mathrm{AC}$ losses of the twisted and untwisted HTSC tapes exposed to an alternating field longitudinal and normal to the length of sample have been investigated. The total losses consist of the hysteresis part of the superconducting cores and the eddy current of the silver sheath.

The hysteresis part of the sample is obtained by taking away the eddy loss from the total loss. It is shown that the test results of untwisted sample correspond to the theoretical estimation. However, the coupling between the filament in the multifilamentary wires contributes additional losses at relatively high external field.

The test results on the $50-\mathrm{mm}$ pitch twisted filament tape show that the losses are slightly lower than that in the untwisted tape. This is due to the reduction of the coupling losses between the filaments in the tape.

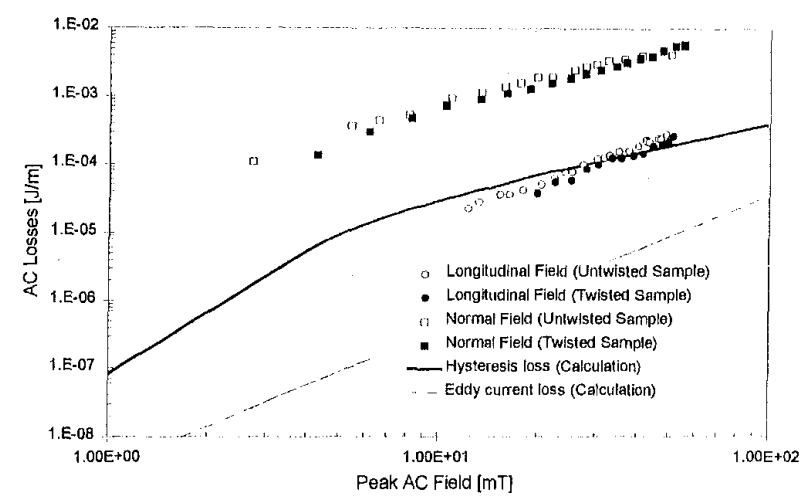

Fig. 9. Normal and longitudinal magnetic loss in twisted and untwisted 37multifilamentary HTSC tapes.

When measuring the losses of the samples that are exposed normally to the field, the losses become about one order higher both for twisted and untwisted samples. This is due to the anisotropic properties of the grains in the superconducting part.

\section{ACKNOWLEDGMENT}

The authors would like to thank Prof. S.X. Dou and Dr. J.X. Jin from the Institute of Superconducting and Electronic Materials of the University of Wollongong for their support. Thanks are also due to Prof. T. Beales and Dr. M. Apperley from the Australian Superconductors.

\section{REFERENCES}

[1] S.W. Schwenterly, J.W. Lue, M.S. Lubell, J.N. Luton and C.H. Joshi, "Critical current measurements on $\mathrm{Ag} / \mathrm{Bi}-\mathrm{Pb}-\mathrm{Sr}-\mathrm{Ca}-\mathrm{Cu}-\mathrm{O}$ composite coils as a function of temperature and external magnetic fields," IEEE Trans. on Appl. Supercond, vol. 3, pp. 949-952, March 1993.

[2] H. Ishii, S. Hirano, T. Hara, J. Fujikami and K. Sato, "The a.c. losses in $(\mathrm{Bi}, \mathrm{Pb})_{2} \mathrm{Sr}_{2} \mathrm{Ca}_{2} \mathrm{Cu}_{3} \mathrm{O}_{\mathrm{X}}$ silver-sheathed superconducting wires," Cryogenics, vol. 36, pp. 697-703, 1996.

[3] M. Ciszek, B.A. Glowacki, A.M. Campbell, S.P. Ashworth, and W.Y. Liang, "Influence of external magnetic field and its orientation on transport $\mathrm{AC}$ losses in Bi-2223 and Tl-1223 silver sheathed tapes," IEEE Trans. on Appl. Supercond., vol. 7, pp. 314-317, June 1997.

[4] T. Hardono, C.D. Cook and J.X. Jin, "Measurements of ac losses in HTSC wires exposed to an alternating field using calorimetric methods," IEEE Trans. on Appl. Supercond, vol. 9, pp. 813-816, June 1999.

[5] W.G. Wang, Z. Han, P. Skov-Hansen, J. Goul, M.D. Bentzon, P. Vase and Y.L. Liu, "High critical current $\mathrm{Ag}$ and $\mathrm{Ag}$ alloy sheathed multifilament Bi-2223 Tapes," IEEE Trans. on Appl. Supercond, vol. 9, pp. 2613-1613, June 1999.

[6] N. Banno, N. Amemiya, A. Mihoichi, M. Ciszek, H. Mukai and K. Ohmatsu, "Penetration loss in BSCCO tape without transport current," IEEE Trans. on Appl. Supercond, vol. 9, pp. 2565-2568, June 1999.

[7] L. Bigoni, E. Cereda, F. Curcio, L. Martini and V. Ottoboni, "Electrical, magnetic and ac loss properties of $\mathrm{Bi}-2223 / \mathrm{Ag}$ (alloy) tapes subjected to bending strain," Paper presented at European Conference on Applied Superconductivity, Sitges, Barcelona, 1999. 